\title{
Perceptions of effective self-care support for children and young people with long-term conditions
}

\author{
Susan Kirk, Susan Beatty, Peter Callery, Linda Milnes and Steven Pryjmachuk
}

Aims and objectives. To: (1) Examine children's/young people's, parents' and professionals'/workers' perceptions of the effectiveness of different models of self-care support, (2) identify factors that support and inhibit self-care and (3) explore how different models integrate with self-care support provided by other organisations.

Background. Childhood long-term illness has been largely overlooked in government policy and self-care support underresearched when compared with adults. There is a lack of evidence on which are the most appropriate models and methods to engage young people and their parents in self-care.

Design. Case study.

Methods. Case studies of six different models of self-care support were conducted using multiple methods of data collection in 2009. Semi-structured interviews were conducted with 26 young people, 31 parents and 36 self-care support providers. A sample of self-care support activities was observed and relevant documents reviewed. Data were analysed using the Framework approach.

Results. The effectiveness of self-care support projects was defined in relation to four dimensions - providing a sense of community, promoting independence and confidence, developing knowledge and skills and engaging children/young people. Self-care support provided by schools appeared to be variable with some participants experiencing barriers to self-management and inclusion. Participants self-referred themselves to self-care support projects, and there was a lack of integration between some projects and other forms self-care support.

Conclusion. This study adds to knowledge by identifying four dimensions that are perceived to be central to effective self-care support and the contextual factors that appear to influence access and experiences of self-care support.

Relevance to clinical practice. Study findings can inform the development of self-care support programmes to meet the needs of individuals, families and communities. In addition, the findings suggest that healthcare professionals need to support schools if young people with long-term conditions are to have the same educational and social opportunities as their peers.

Key words: case study, children, chronic illness, families, nurses, nursing, self-care, self-management, young people

Accepted for publication: 25 October 2011

\section{Introduction}

Self-care is a central theme in health policy in the United Kingdom (UK) and internationally. The reasons for this have been attributed to several factors, including the increasing prevalence of chronic illness, an increase in lay knowledge, consumerism and the desire for personal control and the need to contain escalating healthcare costs [Health Canada, 1997, Wanless 2002, Department of Health (DH) 2005]. However, it has been argued that the potential of self-care to improve
Authors: Susan Kirk, MSc, PhD, RN, Senior Lecturer, School of Nursing, Midwifery and Social Work, University of Manchester; Susan Beatty, MSc, PhD, Cert Ed, Research Associate, School of Community Based Medicine, University of Manchester; Peter Callery, MSc, PhD, RN, Professor, School of Nursing, Midwifery and Social Work, University of Manchester; Linda Milnes, MPhil, PhD, RN, Lecturer, School of Nursing, Midwifery and Social Work, University of Manchester; Steven Pryjmachuk, PhD, RN, PGDipEd,
Senior Lecturer, School of Nursing, Midwifery and Social Work, University of Manchester, Manchester, UK

Correspondence: Susan Kirk, Senior Lecturer, School of Nursing, Midwifery and Social Work, University of Manchester, Jean McFarlane Building, Oxford Road, Manchester M13 9PL, UK. Telephone: +44 (0) 1613067872.

E-mail: sue.kirk@manchester.ac.uk 
health- and system-related outcomes has been overstated in the light of the available evidence (Bury et al. 2005). Moreover, although couched in a patient-centred language, it has been proposed that the self-care policy agenda is a device to transfer the costs and responsibility for care onto patients and families (Coulter \& Ellins 2006).

Increasing numbers of children/young people are living with long-term conditions (Dodge et al. 2007, Daley et al. 2009, RCPCH 2009). They face a lifetime of illness management, and their success in this may influence outcomes in adulthood. However, childhood long-term illness has been largely overlooked in UK government policy relating to self-care. Specific child health policy, while noting the importance of developing children's and parents' self-management skills and need for self-management programmes, does not give self-care significant attention (DH/Department for Education and Skills 2004, DH 2007a, 2009).

Conceptualising self-care in relation to children/young people is complex because of the key role parents play in managing their child's condition as well as the complexity surrounding the transfer of self-care responsibilities from parents to children (Williams et al. 2007, Kirk 2008, Newbould et al. 2008). Consequently, the 'self' in this context is a combination of child and adult carers.

\section{Background}

It has been proposed that self-care support should enable individuals to perform three tasks: medical management of their condition, carrying out normal roles and activities and managing the emotional impact of their condition (Lorig \& Holman 2003). Although self-care support is embedded (at least philosophically) within the 'routine' care of many professionals, in the context of a long-term condition, it is largely associated with particular interventions such as educational and skills training programmes or self-care support devices (DH 2007b). Consequently, self-care support has been constructed largely in terms of the individual patient rather than the structural constraints influencing self-care. It has been highlighted that flexibility in provision is needed to enable individuals to access a range of different types of support from both formal and informal self-care resources as well as support that takes account of their socio-economic and cultural contexts (Bury et al. 2005, Corben \& Rosen 2005). In addition, a more comprehensive approach to selfcare has been advocated with interventions directed not only at patients but at professionals and the health system (Kennedy et al. 2007).

Self-care support for children/young people has been under-researched when compared with adults. A range of interventions for children/young people have been developed and evaluated by researchers with different aims, target groups, methods and settings (Kirk et al. 2010). Their main focus has been on condition management and information provision while the psychosocial aspects of living with a longterm condition have received less attention (Barlow \& Ellard 2004).

There is evidence to suggest interventions that aim to enhance self-care in relation to children/young people can be effective in improving a range of outcomes such as health status, quality of life, adherence, condition-related knowledge and coping skills (Davis et al. 2004, Cicutto et al. 2005, Franklin et al. 2006, Jan et al. 2007). In terms of effect on health service use, there are mixed findings with studies reporting both no reductions (Guendelman et al. 2002, Stevens et al. 2002, McPherson et al. 2006) and significant reductions (Wesseldine et al. 1999, Cicutto et al. 2005). There is some evidence that interventions focusing on professionals or service systems may be effective in improving health status and reducing health service use (Clark et al. 2000, Lozano et al. 2004). Studies examining participants' views have discovered that children/young people and parents value group-based self-care interventions for the opportunity they provide to interact with others in a similar situation (Johnson et al. 2001, Bruzzese et al. 2004, Trollvik \& Severinsson 2005). Interventions that use e-health methods for selfmanagement support have also been found to be usable and appropriate (Gammon et al. 2005, Franklin et al. 2006, Van der Meer et al. 2007).

The study reported in this paper focused on asthma, diabetes, cystic fibrosis (CF) and attention-deficit hyperactivity disorder (ADHD) - four long-term conditions that differ in terms of self-care management complexity, prognosis and potential for involvement of different health and social care organisations. This paper reports the findings from the final stage of a larger study that aimed to describe and evaluate current self-care support models for children/young people with long-term conditions (Kirk et al. 2010). The term 'model' in this study was used conceptually to describe an approach to self-care support comprised of different components.

\section{Methods}

The aims of the study were to:

1 Examine children's/young people's, parents' and professionals'/workers' perceptions of the effectiveness of different models of self-care support.

2 Identify factors that support and inhibit self-care at an organisational and individual level. 
3 Explore how different models of self-care support integrate with self-care support provided by other organisations.

A case study approach enabled self-care support to be explored in its real-life context and from the perspectives of different stakeholders (Yin 2008). The 'case' (unit of analysis) was defined as being a self-care support project. Multiple comparative case studies were included to assist the descriptive and explanatory analysis and reveal different contextual issues.

\section{Sampling and recruitment}

As part of the larger study, a national survey was conducted to identify self-care support projects for children/young people with long-term conditions. Information on the conduct of this stage of the research is provided elsewhere (Kirk et al. 2010). This survey developed a sampling frame of 70 self-care support projects from which six were purposefully sampled to reflect different ways of providing self-care support as well as ones that were condition and noncondition specific.

Sampling of participants was informed by the characteristics of the particular self-care support project in terms of its target group(s) and the types of activities provided. Sampling was purposeful to include variation in terms of children's/ young people's ages and different types of workers/roles (e.g. unpaid volunteers, nurses, doctors, therapists, project managers). Attempts were made to include children/young people and parents who had 'dropped out' of projects. Parents and children/young people were recruited via projects.

\section{Data collection}

Multiple methods of data collection were used to enable the development of a more complete picture of self-care support. These were semi-structured interviewing, observation and documentary review. Data were collected in 2009.

Semi-structured interviews were conducted with children/ young people, parents and workers to explore their views and experiences of the particular self-care support project and their perceptions of its appropriateness and effectiveness. Interviews were conducted mainly by telephone although face-to-face interviews were conducted where it was the participant's preference. Non-participant observation of a sample of activities was conducted at two case studies to examine the context, content, processes and the interactions occurring (Table 2). Virtual non-participation methods were used for an online support group that involved observing and downloading discussion group postings. Where available, documents were collected relating to each self-care support project's development and implementation to provide background information to contextualise the findings.

\section{Data analysis}

Data were analysed using the Framework approach (Ritchie \& Spencer 1994). A framework was developed to classify and summarise the data for each case study based on the study aims, self-care project characteristics and themes emerging from the interviews and observations. This approach was taken to ensure the analysis focused on the study aims while being grounded in participants' own accounts. Data charts were used to develop descriptions of themes and their dimensions, explore associations and search for explanations. This enabled comparisons to be made both between and within self-care support projects.

\section{Research ethics}

National Health Service (NHS) research ethics committee approval was obtained. For children/young people under 16 years of age, parental consent for their child's participation was obtained as well as the young person's written assent as the final decision on participation rested with the child/ young person. Procedures were established to manage the occurrence of distress and child protection disclosures. Participants were anonymous and any potentially identifying characteristics altered.

\section{Findings}

The characteristics of the self-care support projects are presented in Table 1. Table 2 presents the numbers of interviews conducted at each site and sample characteristics. The findings from the study will be presented as a cross-case analysis, organised around the main themes emerging from the Framework Analysis. Table 3 summarises the relationship of these themes to the individual case study sites.

\section{The context to accessing self-care support}

The contextual background against which parents and children/young people made decisions about accessing selfcare support and conceptualising effectiveness was their experiences of living with chronic illness which centred on 'managing the condition' and 'being different'.

Living with a long-term condition involved parents and children/young people in the daily management of symptoms, triggers and therapeutic regimens. Over time, parents 


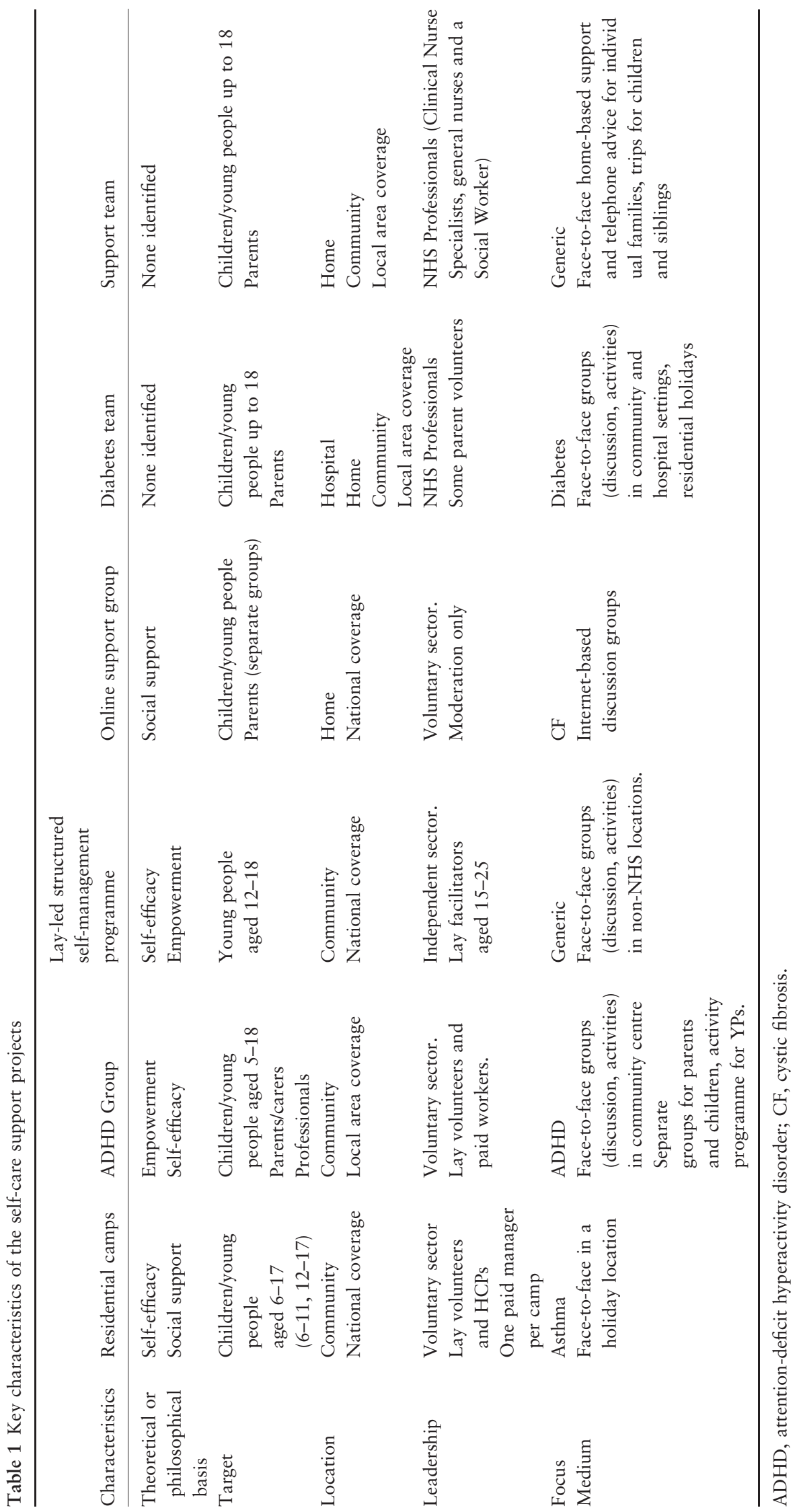


Table 2 Study sample and data collection

\begin{tabular}{|c|c|c|c|c|c|}
\hline $\begin{array}{l}\text { Self-care support } \\
\text { project }\end{array}$ & $\begin{array}{l}\text { Interviews with } \\
\text { children and } \\
\text { young people }\end{array}$ & $\begin{array}{l}\text { Interviews } \\
\text { with parents }\end{array}$ & $\begin{array}{l}\text { Interviews } \\
\text { with professionals } \\
\text { and workers }\end{array}$ & Total & Observation \\
\hline Asthma camps & 6 & 5 & 10 & 21 & One day of an asthma camp \\
\hline ADHD Centre & 4 & 7 & 11 & 22 & $\begin{array}{l}\text { Six hours of a skills building } \\
\text { workshop }(3 \times 2 \text { hour sessions }) \\
\text { for parents. Six hours of a skills } \\
\text { building workshop } \\
(6 \times 1 \text { hour sessions }) \text { for } \\
\text { children }\end{array}$ \\
\hline $\begin{array}{l}\text { Lay-led structured } \\
\text { self-management } \\
\text { programme* }\end{array}$ & 10 & 6 & 6 & 22 & None \\
\hline Online support group $^{\dagger}$ & N/A & N/A & 1 & 1 & $\begin{array}{l}\text { Four months of discussion } \\
\text { group postings ( } 153 \text { threads) }\end{array}$ \\
\hline Diabetes team & 2 & 6 & 6 & 14 & $\begin{array}{l}\text { Two hours of a club for } \\
\text { children with diabetes }\end{array}$ \\
\hline Support team & 4 & 7 & 2 & 13 & None \\
\hline Total & $\begin{array}{l}26 \\
(14 \text { male, } 12 \text { female }) \\
(\text { Aged } 8-11 \text { years }=7, \\
\text { aged } 12-15 \text { years }=12, \\
\text { aged } 16-18 \text { years }=7)\end{array}$ & $\begin{array}{l}31 \\
\text { (26 mothers, } \\
5 \text { fathers) }\end{array}$ & 36 & 93 & \\
\hline
\end{tabular}

ADHD, attention-deficit hyperactivity disorder.

*Recruited from six courses across England.

Data collection at this site was mainly observation of discussion group postings.

described how they had developed the expertise and knowledge to manage their child's condition. Children/young people regarded needing medication and therapy regimens as part of 'normal' life as most had had a long-term condition since infancy. Parents described how they had supported their children in gradually acquiring responsibility for managing their own health. Initially, this process had commenced by encouraging them to 'know' their own bodies, to be able to articulate symptoms to others and decide on the actions needed. Over time, parents provided opportunities for children to become involved in aspects of managing their condition and in taking increasing control over decisionmaking. However, children's/young people's enthusiasm for becoming responsible for self-management varied as well as the particular aspects they wanted to be involved in. Even when responsibilities had been transferred, parents continued to play a surveillance role, discretely monitoring their children's health and self-care.

The school emerged as a problematic context for self-care because of a lack of understanding and awareness about children's conditions. The consequences of this were that selfcare could be unsupported and appropriate adjustments not made for children's needs. The support that children/young people needed at school varied, it could be for clinical care provision (e.g. insulin administration), supervision of self- management or it could be educational rather than healthrelated support. The additional support provided in school was variable with some children being provided with support workers but others having no support. Consequently, some parents and children/young people could face considerable barriers to self-care in school. For parents, this could mean that they had to go into schools on a daily basis and go on school:

I go in to inject. Our school isn't too keen on that side of it at the moment... I go at the moment on the trips. I mean at the moment, the other children are all very accepting of seeing me there and what I do.... but as he gets older, you don't really know how that might go (Parent 05p04)

Parents of children/young people with asthma in particular described how primary schools created barriers to selfmanagement by not allowing children/young people to keep their inhalers with them. This undermined what children/ young people were being taught at the asthma camps. Action plans to support self-care could be developed in collaboration with healthcare staff but then not implemented by the school:

They've got nobody there to be able to supervise Sam in doing this, so I've had the hospital in at school, ... and a plan was set up, but that plan has never been, it's never took place (Parent 01p05) 


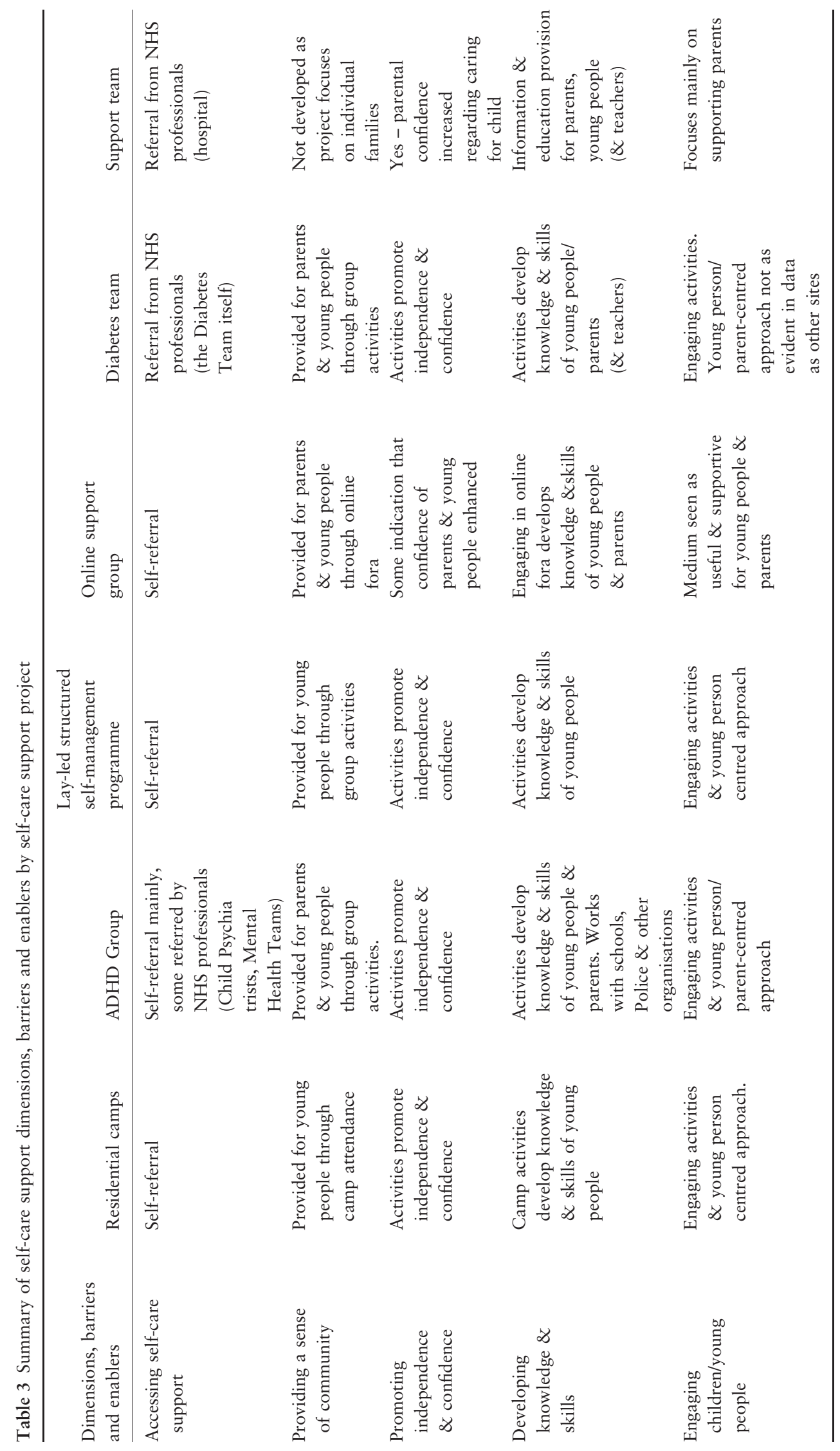


$S$ Kirk et al.

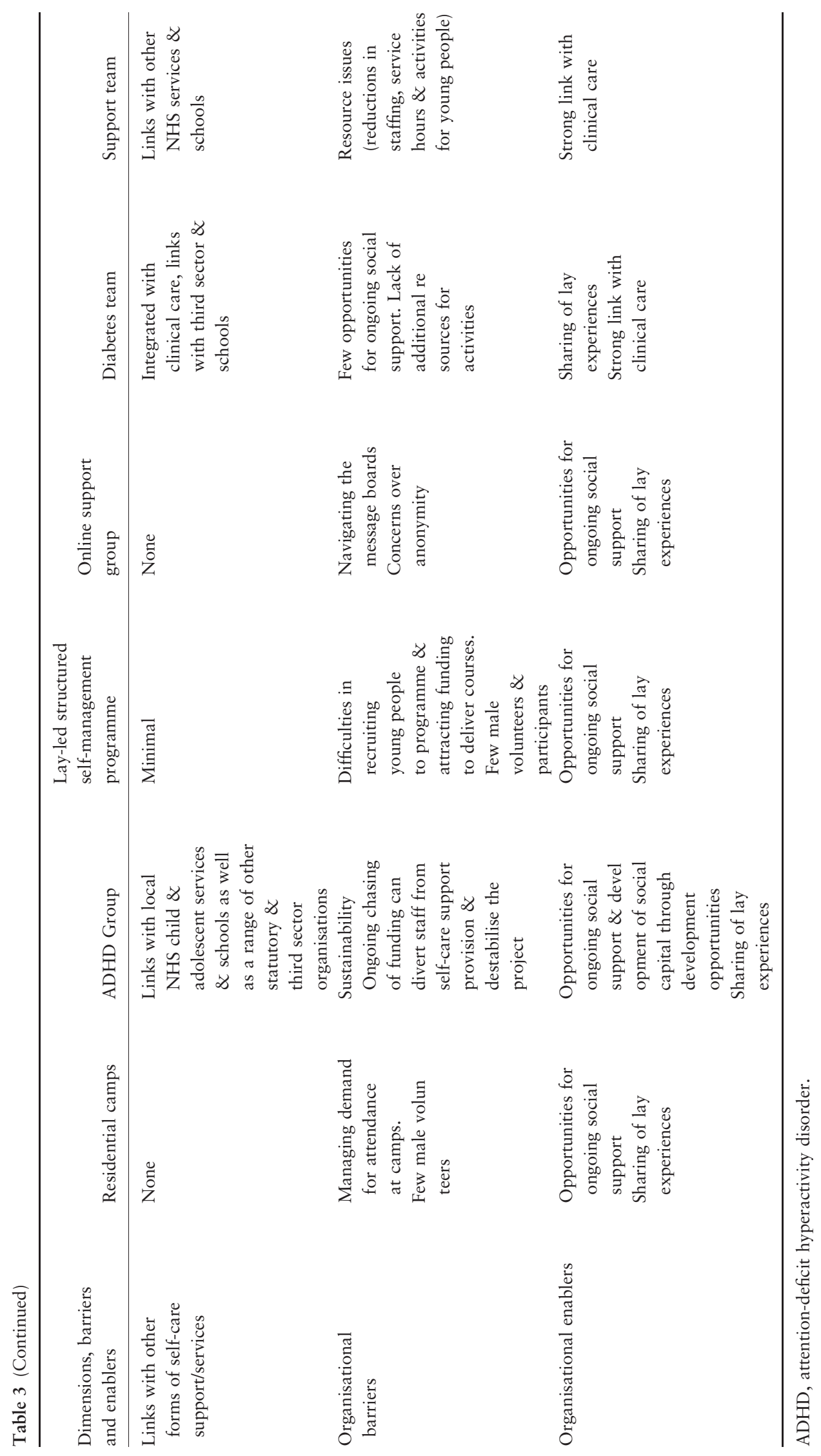


Children/young people described feeling different to their peer group and from their accounts it appeared that situations that gave rise to these feelings occurred mainly in school. These situations included the need to carry medical equipment, conduct self-management activities and encounter physical limitations (or having limitations placed on them by schools):

At lunch, just before I eat, I have to go into the nurse's office, because we have a nurse at our school and do it there. (Young Person 03yp03)

Parents were aware of children's feelings of difference arising from carrying out self-management activities at school:

She was a bit wary when she was little, sort of doing it in front of people, especially because she had the spacer, you know, when you're little it kind of looks like you, you're a bit of a freak. (01p04)

A consequence of feeling different was a sense of isolation for children/young people, particularly if they were the only child in their school or class with a medical condition.

\section{Accessing self-care support}

Families had referred themselves to self-care support projects in most instances as a result of receiving information directly from nurses or teachers or hearing about projects through lay networks or project marketing. Apart from the ADHD Centre, it appeared that non-NHS projects were poorly linked into NHS referral/care pathways. The NHS-led projects were closely integrated with clinical care which appeared to promote continuity and consistency of support and enhance relationships between young people, parents and clinicians.

Indeed, access to projects appeared to be promoted when a health professional or other worker discussed the project individually with a young person or parent:

the fact that she sent the letter to Amy and said, oh Amy this looks really interesting, would you like to get involved? Yeah we probably wouldn't have just picked that up at the clinic, it's probably the fact that she said oh, what do you think about this, we thought, well yeah actually that probably could be quite beneficial. (Parent 03p01)

Children/young people highlighted how parents (largely mothers) played a key role in their decision to participate through their encouragement to attend. When parents' and children's/young people's reasons for accessing projects were examined, it appeared that they saw the project as a means of reducing their sense of isolation by providing an opportunity to meet with others in a similar situation to themselves:

you do feel quite isolated, so it was a chance to, to meet others really, going through the same thing... giving Joe a chance to see other children, so perhaps he doesn't feel so isolated as well (Parent 05p04)
Parents in particular wanted to learn more about their child's condition or develop management strategies. They also saw projects as a way of promoting their child's independence:

because he was desperate to go somewhere and be a bit more independent and he said he'd quite like to do that, so, he signed up for it (Parent 01p03)

Participants noted however that parents or children/young people had to be at a stage in their illness trajectory when they felt 'ready' to access such self-care support projects:

I think it depends where people are at with their condition, I think, you know, it depends whether they're still, there's so many stages ... I think your head's got to be in a certain place to gain the most from it' (Young person 03yp02)

\section{Perceptions of the effectiveness of self-care support}

Participants defined the effectiveness of self-care support projects in relation to four dimensions - providing a sense of community, promoting independence and confidence, developing knowledge and skills and engaging children/young people.

\section{Providing a sense of community}

Participants highlighted the importance of the self-care project in providing a sense of community for children/young people and parents, which enabled the provision of social support as well as extending participants' social networks. In addition, as will be presented later, it was also a site for the exchange of experiential knowledge and the development of self-confidence.

Parents and children/young people described how before participating in the project they had felt alone but that accessing the project had led them to recognise that there were others in the same situation and coping with similar feelings and issues:

It makes you feel that you're not alone, makes you feel that you're not the only one, the only child that feels different (Young person 06yp01)

The good thing of having a group is that, that you're so isolated at the beginning, you're on your own and you feel nobody understands, nobody feels what I'm feeling....when you come here and when a person talks, they're saying your life, they don't know you, but they're saying the things that are going on in your life and you think, oh my God, I'm not alone (Parent 02p03)

This community was seen as providing a safe place where feelings and experiences could be expressed and discussed with those who would understand: 
It was nice to know that there were other people who felt the same way as me, I kind of, before I went on that course, I didn't really want to talk about my condition and I just didn't really want to tell anyone that I had it, but then I realised it wasn't a bad thing and that I just happened to have a condition, I was a normal teenager. And so I kind, it gave me more confidence to actually talk about it and I realised that people were actually really supportive (Young person 03yp03)

For many children/young people, participating in the project was first time they saw others self-managing a long-term condition that was viewed as a way of increasing their confidence about self-management in public:

It was really good spending a weekend with people that, like where everybody is in the same boat and like everybody's having to sit down at lunchtime and take loads of medication and sort themselves out and not have to like hide it (Young person 04YP01)

From participants' accounts, it appeared that embedded in the social support provided by projects was a normalisation of chronic illness as projects were settings where illness management and experiences were normalised.

In some instances, friendships developed which were maintained beyond the project but some participants felt a sense of loss when projects ended unless there were opportunities to move into volunteer roles or remain connected with projects in other ways as a means of maintaining support.

\section{Promoting independence and confidence}

Participants associated effectiveness with the promotion of young people's independence and self-confidence. Activities that enabled children/young people to manage their condition independently in a supportive environment were seen as enhancing independence and self-confidence. This had the potential to increase parent's confidence in transferring responsibility to their children and thus increase their independence.

Providing children/young people with the opportunity to take part in challenging activities (e.g. abseiling) was seen as building their self-esteem as well as demonstrating to parents their capabilities and appropriate limitation boundaries. As noted earlier, meeting others with a long-term condition could promote self-confidence because of young people recognising they were not alone in living with chronic illness:

it made me more confident with it, because before I didn't really know many people that had asthma and I kind of used to feel very odd, especially with a big bag with a big spacer in it, but um, yeah, it made me more confident with it (Young person 01yp04)

\section{Developing knowledge and skills}

Participants described how projects had developed their condition-related knowledge and understanding. Parents of children/young people with ADHD described how they had gained both knowledge about the condition and understanding of their child and their behaviour:

the course has benefited me in the fact that I understand my son now ... I used to look at him as a naughty child ... I used to think at times is he doing this to drive me mad? ... it's made me look at Daniel in a different light, I now look at him to say, well look he's got, he's not a problem, he's got a problem and he needs, he needs our help, the best way we can (Parent 02p07)

Children/young people were also described gaining knowledge and understanding from project participation which enhanced their capacity for self-management:

it helps me understand more about asthma and what happens inside your body. (Young person 01yp05)

The knowledge derived from self-care support projects came from both formal and informal sources. Parents and children/ young people learned from one another about long-term conditions, self-management and accessing support:

We'd like bounce ideas off each other. If people said, oh you could try doing this and then, yeah, kind of developing ideas between ourselves. (Young person 05yp02)

Experiential knowledge was developed not only from contact with the other participants but also through the involvement of volunteers/workers with the same condition. Their ability to empathise with participants because of their personal experience as well as their potential to act as role models, successfully managing their condition and taking part in activities, was seen as enabling self-care.

In addition to developing condition-related knowledge, participants developed their skills in managing their or their child's condition. Parents at the ADHD Centre described how they had learned to manage their child's behaviour by attending a skills-based course:

It really helped me, it's, well, before, before I went on the course I wasn't focusing on his good behaviour and ignoring his naughty behaviour (Parent 02p04)

Children/young people also described learning how to manage their condition:

We learnt about anger... I go upstairs to my bedroom I just sit down and have a time out (Young person 02yp02) 
Self-care support projects helped young people develop their communication skills with professionals such as doctors and teachers. This appeared to be a consequence of increased condition-related knowledge as well as an outcome of communication skills training:

One thing for me that really stands out was communication skills, where we talked about how we should talk to doctors and how to talk to teachers, things like that....... after I went on the course I actually started telling my teachers what was wrong with me and they were really, really supportive and they gave me all the help that I needed and it was a really crucial time, 'cause it was like the beginning of my A Levels (Worker 04w03)

In addition, children/young people developed the language, skills and self-confidence to explain their condition to others:

Before I kind of didn't really tell anyone about my condition and now it's just it's fine I can talk about it and say you know, I can't do this because I've got a condition and people understand and so I think if it wasn't for that course, I would never have done that really, I would have thought that it would have been a really bad thing to start talking about it. (Worker 03w03)

\section{Engaging children/young people}

The ability of self-care support projects to engage young people was seen as important. In addition to being educational, activities had to be perceived by children/young people as enjoyable as well as gender and age appropriate. It was important that workers were approachable, non-judgemental and actively listened to young people's views:

you just get listened to and like your opinion actually does count, they don't just go 'oh, look they're saying something again' it's like, it's so what do you think about that (Young person 02yp04)

Some workers emphasised how being 'young person friendly' included incorporating children's/young people's ways of communicating into the project. The Diabetes Team used email as a means of answering questions about self-management and was beginning to use texting for reminders about appointments. The use of an online support group appeared to engage children/young people and was seen as an important means of obtaining social support and information.

\section{Discussion}

This is the first study to evaluate self-care support for children/young people across different long-term conditions and models to examine how participants access self-care support, how effectiveness is defined and what barriers and enablers are at play. In common with other studies of living with childhood chronic illness and disability, children's/ young people's and parents' experiences were associated with the 'routinisation' of daily life by illness management work, feelings of difference and disclosure negotiation (Christian \& D’Auria 1997, Atkin \& Ahmad 2000, 2001, Herrman 2006). The motivations underpinning access related directly to these experiences as well as needs for information and skills training. The route into self-care support projects was largely by self-referral and although in some instances nurses and teachers provided information about self-care support projects, projects were not part of referral pathways (excluding the two NHS sites). This reflects the nature of the relationships and lack of integration between some projects and other forms self-care support. The findings from this study suggest that access may be enhanced when self-care support projects are promoted on an individual child/family basis by healthcare professionals and that parents' role in encouraging young people's access to self-care projects and maintaining their involvement needs recognition. The importance of maintaining parental involvement through adolescence has been noted in other studies (La Greca et al. 1995, Anderson et al. 1997). Schools emerged as an important site for illness and identity management, yet their capacity to support children/young people appeared to be variable. Indeed, schools could create barriers to self-care and participation in school activities in spite of government guidance on supporting young people with long-term conditions (DfES/ DH 2005).

The effectiveness of self-care support was defined in relation to four dimensions - providing a sense of community, promoting independence and confidence, developing knowledge and skills and engaging children/young people. Group-based approaches (either face-to-face or virtual) provided participants with a sense of community reducing their feelings of social isolation by normalising chronic illness and developing social networks. In addition, groups were important mechanisms for learning about long-term conditions and self-management through the sharing of experiences, information and strategies. These findings are supported by other research (Johnson et al. 2001, Bruzzese et al. 2004, Trollvik \& Severinsson 2005). However, groupbased approaches will not be a universally acceptable method of self-care support and its potential to lead to the construction of negative social comparisons needs consideration (Rogers et al. 2009).

Projects were seen as providing children/young people with the opportunity to develop their independence and confidence both socially and in terms of self-management. 
This occurred through participation in challenging activities and young people's recognition of their own ability to manage their social relationships and health. Participating in self-care support projects developed parents' and children's/ young people's formal and experiential forms of knowledge about long-term conditions, their self-management skills and, for children/young people in particular, their communication skills. Other research has suggested that self-care support can enable children/young people to improve their communication skills with professionals and parents (Salinas 2007). The fourth dimension to effectiveness was engaging children/young people through providing activities that make learning fun and developing a child/young person centred culture where their views are listened to and respected and their preferred means of communication for self-care used. Another study examining self-care support similarly identified the importance placed by children/young people on the approachability and interpersonal skills of health professionals, in particular their ability to listen and be receptive to individual needs (Anderson 1997). There is a developing body of evidence suggesting that e-health methods are an acceptable, engaging, feasible and effective method of providing self-care support to children/young people with long-term conditions (Davis et al. 2004, Gammon et al. 2005, Franklin et al. 2006, Van der Meer et al. 2007).

\section{Strengths and limitations of the study}

This study has contributed to knowledge about how effective and appropriate self-care support can be developed. Although the findings from the study cannot be considered to be generalisable in a quantitative sense, the sample size is large for a qualitative study, has been drawn from a range of approaches to self-care support and has used multiple methods of data collection. The sample may only include those wishing to access self-care support and who do not experience barriers to access. It proved impossible to recruit 'drop-outs' from study sites which raises the possibility that the sample is skewed to those who are more satisfied. However, participants appeared to be candid, expressing both positive and negative views about projects.

\section{Conclusions}

This study has revealed that effectiveness of self-care support is defined in relation to four dimensions: - providing a sense of community, promoting independence and confidence, developing knowledge and skills and engaging children/ young people. Self-care support in schools appears to be variable with some children experiencing barriers to selfmanagement and inclusion. Promoting self-care support on an individual child/family basis by healthcare professionals

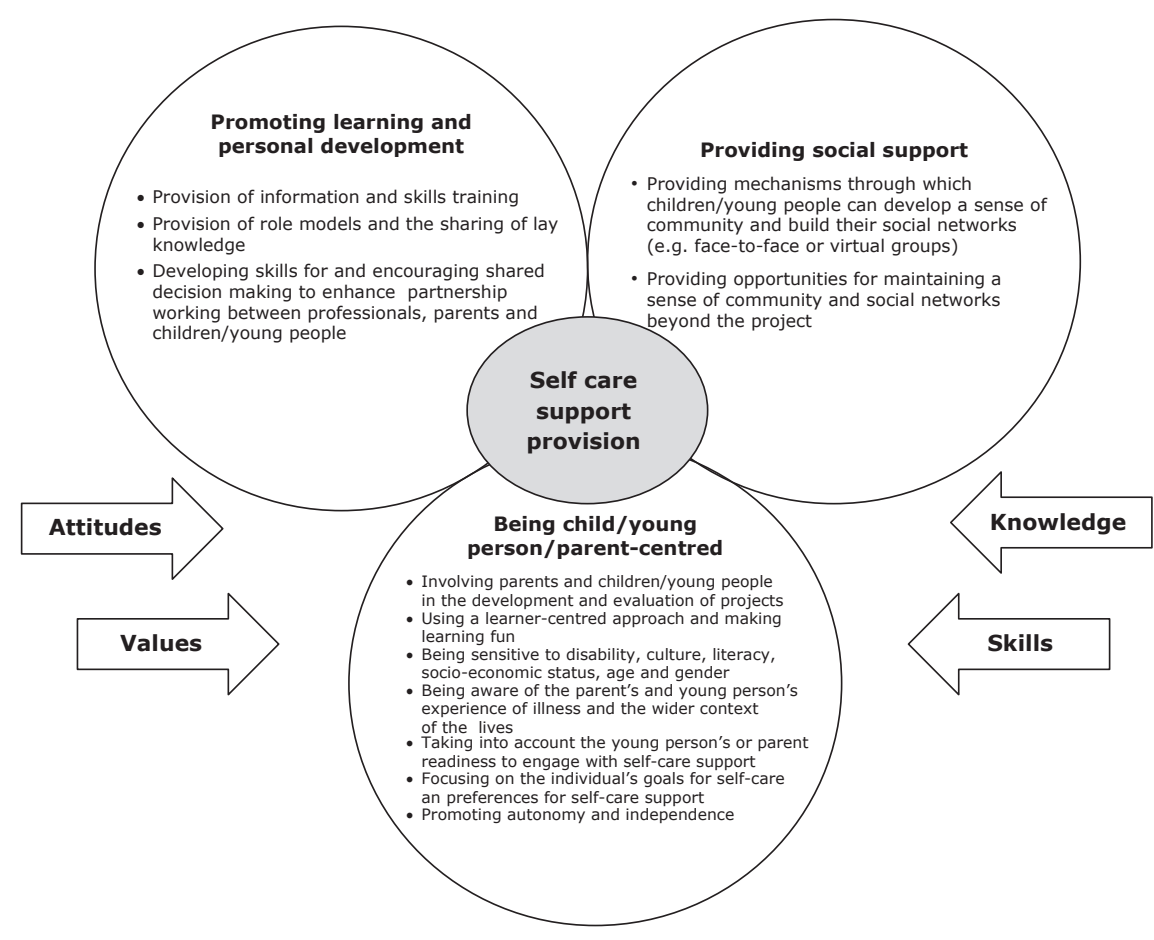

Figure 1 Components of self-care support provision. 
and maintaining parental involvement appear to be important factors in encouraging young people to access self-care support.

\section{Relevance to clinical practice}

The four dimensions perceived to be central to effective selfcare support and the contextual factors that appear to influence access and experiences of self-care support can be used by practitioners and policy makers to inform the development of self-care support programmes, resources and tools to meet the needs of individuals and communities. Figure 1 presents the elements this study suggests should underpin or be incorporated in a 'menu' of choices for selfcare support. Similar components have been identified in relation to adults (Health Canada 1997). Fundamentally, the values, attitudes, knowledge and skills necessary to support self-care need to be embedded within education programmes and professional practice.

Integration of self-care support between third sector and health service organisations would enable the delivery of complementary forms of support. Health service involvement enables the integration of self-care support with clinical care while third sector organisations bring lay knowledge and understandings to self-care support. The inclusion of projects in referral pathways would ensure access is promoted for all families. Although guidance has been developed for medicines management in schools that emphasises the importance of supporting young people's own self-management and participation in activities (DfES/DH 2005), this study suggests that self-care support by schools needs improving. It may be that additional and ongoing support by healthcare professionals is needed to support schools to ensure that young people with long-term conditions have the same educational and social opportunities as their peers.

\section{Acknowledgements}

The researchers would like to thank the research participants for sharing their experiences, the self-care projects for participating in the study and for providing valuable help with recruitment, and the reference group and young people's advisory group for their insight and guidance.

This project was funded by the National Institute for Health Research Service Delivery and Organisation (SDO) programme. The views and opinions expressed therein are those of the authors and do not necessarily reflect those of the NIHR SDO programme or the Department of Health.

\section{Contributions}

Study design: SK, PC, LM, SP; data collection and analysis: SK, SB, PC, LM, SP and manuscript preparation: SK, PC, LM, SP.

\section{Conflict of interest}

None.

\section{References}

Anderson J (1997) An evaluation of an adolescent diabetes education program. Canadian Journal of Diabetes Care 21, 28-33.

Anderson B, Ho J, Brackett J, Finkelstein D \& Laffel L (1997) Parental involvement in diabetes management tasks: relationships to blood glucose monitoring adherence and metabolic control in young adolescents with insulin-dependent diabetes mellitus. Journal of Pediatrics 130, 257-265.

Atkin K \& Ahmad WIU (2000) Family caregiving and chronic illness: how parents cope with a child with a sickle cell disorder or thalassaemia. Health and Social Care in the Community 8, 57-69.

Atkin K \& Ahmad W (2001) Living a 'normal' life: young people coping with thalassaemia major or sickle cell disor- der. Social Science of Medicine 53, 615-626.

Barlow J \& Ellard DR (2004) Psychoeducational interventions for children with chronic disease, parents and siblings: an overview of the research evidence base. Child: Care, Health and Development 30, 637-645.

Bruzzese JM, Bonner S, Vincent E, Sheares B, Mellins RB, Levison MJ, Wieseman S, Du Y, Zimmerman BJ \& Evans D (2004) Asthma education: the adolescent experience. Patient Education and Counselling 55, 396-406.

Bury M, Newbould J \& Taylor D (2005) A Rapid Review of the Current State of Knowledge Regarding Lay-Led Self-Management of Chronic Illness: Evidence Review. National Institute for Health and Clinical Excellence, London.
Christian BJ \& D'Auria JP (1997) The child's eye: memories of growing up with cystic fibrosis. Journal of Pediatric Nursing 12, 3-12.

Cicutto L, Murphy S, Coutts D, O’Rourke J, Lang G, Chapman C \& Coates P (2005) Breaking the access barrier: evaluating an asthma center's efforts to provide education to children with asthma in schools. Chest 128, 1928-1935.

Clark N, Gong M, Schrock M, Kaciroti N, Evans D, Roloff D, Hurwitz M, Mairman L \& Mellins R (2000) Long term effects of asthma education for physicians on patient satisfaction and use of health services. European Respiratory Journal 16, 15-21.

Corben S \& Rosen R (2005) Self-Management for Long-Term Conditions: Patients' Perspectives on the Way Ahead. Kings Fund, London. 
Coulter A \& Ellins J (2006) Patient-Focused Interventions: A Review of the Evidence. The Health Foundation, London.

Daley D, Jones K, Hutchings J \& Thompson M (2009) Attention deficit hyperactivity disorder in pre-school children: current findings, recommended interventions and future directions. Child: Care, Health and Development 35, 754-766.

Davis MA, Quittner AL, Stack CM \& Yang MC (2004) Controlled evaluation of the STARBRIGHT CD-ROM Program for children and adolescents with cystic fibrosis. Journal of Pediatric Psychology 29, 259-267.

Department for Education and Skills/ Department of Health (2005) Managing Medicines in Schools and Early Years Settings. DfES, London.

Department of Health (2005) Self Care - A Real Choice: Self Care Support - A Practical Option. The Stationery Office, London.

Department of Health (2007a) Making Every Young Person with Diabetes Matter. Department of Health, London.

Department of Health (2007b) Research Evidence on the Effectiveness of Self Care Support (Work In Progress 200507). Department of Health, London.

Department of Health (2008) Core Principles to Support Self-Care. Department of Health, London.

Department of Health (2009) Healthy Lives, Brighter Futures. Department of Health, London.

Department of Health and Department for Education and Skills (2004) National Service Framework for Children, Young People and Maternity Services: Children and Young People who are Ill. Department of Health, London.

Dodge JA, Lewis PA, Stanton M \& Wilsher J (2007) Cystic fibrosis mortality and survival in the UK: 1947-2003. European Respiratory Journal 29, 522-526.

Franklin VL, Waller A, Pagliari C \& Greene SA (2006) A randomized controlled trial of Sweet Talk, a text-messaging system to support young people with diabetes. Diabetic Medicine 23, 13321338.

Gammon D, Arsand E, Walseth O, Andersson N, Jenssen M \& Taylor T (2005) Parent child interaction using a mobile phone wireless system for blood glucose monitoring. Journal of Medical Internet Research 7, e57 1-9.

Guendelman S, Meade K, Benson M, Chen Y \& Samuels S (2002) Improving asthma outcomes and self-management behaviors of inner-city children: a randomized trial of the health buddy interactive device and an asthma diary. Archives of Pediatrics and Adolescent Medicine 156, 114-120.

Health Canada (1997) Supporting SelfCare: The Contribution of Nurses and Physicians. Health Canada, Ottawa, ON.

Herrman J (2006) Children's and young adolescent's voices: perceptions of the costs and rewards of diabetes and its treatment. Journal of Pediatric Nursing 21, 211-221.

Jan RL, Wang JY, Huang MC, Tseng MS, Su HJ \& Liu LF (2007) An internetbased interactive telemonitoring system for improving childhood asthma outcomes in Taiwan. Telemedicine Journal and E-Health 13, 257-268.

Johnson KB, Ravery RD \& Everton A (2001) Hopkins Teen Central: assessment of an internet based support system for children with cystic fibrosis. Pediatrics 107, e24.

Kennedy A, Rogers A \& Bower P (2007) Support for self care for patients with chronic disease. BMJ 335, 968-970.

Kirk S (2008) Transitions in the lives of children with complex healthcare needs. Child: Care, Health and Development 34, 567-575.

Kirk S, Beatty S, Callery P, Milnes L \& Pryjmachuk S (2010) Evaluating SelfCare Support for Children and Young People with Long-Term Conditions. National Institute for Health Research Service Delivery and Organisation Programme, Southampton.

La Greca AM, Auslander WF, Greco P, Spetter D, Fisher EB Jr \& Santiago JV (1995) I get by with a little help from my family and friends: adolescents' support for diabetes care. Journal of Pediatric Psychology 20, 449-476.

Lorig KR \& Holman H (2003) Self-management education: history, definition, outcomes and mechanisms. Annals of Behavioral Medicine 26, 1-7.

Lozano P, Finkelstein J, Carey V, Wagner E, Inui $\mathrm{T}$, Fuhlbrigge $\mathrm{A}$, Soumerati $\mathrm{S}$, Sullivan S, Weiss S \& Weiss K (2004) A multisite randomised control trial of the effects of physician education and organisational change in chronic asthma care. Archives of Pediatrics and Adolescent Medicine 158, 875883.

McPherson A, Glazebrook C, Forster D \& James C (2006) A randomised controlled trial of an interactive educational computer package for children with asthma. Pediatrics 117, 10461049.

Newbould J, Smith F \& Francis SA (2008) 'I'm fine doing it on my own': partnerships between young people and their parents in the management of medication for asthma and diabetes. Journal of Child Health Care 12, 116128.

RCPCH (2009) Growing Up With Diabetes: Children and Young People with Diabetes in England. RCPCH, London.

Ritchie J \& Spencer L (1994) Qualitative data analysis for applied policy research. In Analysing Qualitative Data (Bryman A \& Burgess RG eds). Routledge, London and New York, pp. 172-194.

Rogers A, Gately C, Kennedy A \& Sanders C (2009) Are some more equal than others? Social comparison in self-management skills training for long-term conditions. Chronic Illness 5, 305317.

Salinas M (2007) Evaluation Study of the Staying Positive Pilot Workshops: A Self-Management Programme for Young People with Chronic Conditions. Department of Public Health, University of Oxford, Oxford.

Stevens CA, Wesseldine LJ, Couriel JM, Dyer AJ, Osman LM \& Silverman M (2002) Parental education and guided self-management of asthma and wheezing in the preschool child: a randomised controlled trial. Thorax 57, 39-44.

Trollvik A \& Severinsson E (2005) Influence of an asthma education program on parents with children suffering from asthma. Nursing and Health Sciences 7, 157-163.

Van der Meer V, van Stel H, Detmer SB, Otten W, Sterk P \& Sont JK (2007) Internetbased self-management offers an opportunity to achieve better asthma control in adolescence. Chest 132, 112-119.

Wanless D (2002) Securing our Future Health: Taking a Long-term View 
(Final Report). HM Treasury, London.

Wesseldine LJ, McCarthy P \& Silverman M (1999) Structured discharge procedure for children admitted to hospital with acute asthma: a randomised con- trolled trial of nursing practice. Archives of Disease in Childhood 80, 110-114.

Williams B, Mukhopadhyay S, Dowell J \& Coyle J (2007) From child to adult: an exploration of shifting family roles and responsibilities in managing physiotherapy for cystic fibrosis. Social Science \& Medicine 65, 2135-2146.

Yin RK (2008) Case Study Research: Design and Methods. Sage, London.

The Journal of Clinical Nursing (JCN) is an international, peer reviewed journal that aims to promote a high standard of clinically related scholarship which supports the practice and discipline of nursing.

For further information and full author guidelines, please visit JCN on the Wiley Online Library website: http:// wileyonlinelibrary.com/journal/jocn

\section{Reasons to submit your paper to JCN:}

High-impact forum: one of the world's most cited nursing journals and with an impact factor of $1 \cdot 228-$ ranked 23 of 85 within Thomson Reuters Journal Citation Report (Social Science - Nursing) in 2009.

One of the most read nursing journals in the world: over 1 million articles downloaded online per year and accessible in over 7000 libraries worldwide (including over 4000 in developing countries with free or low cost access).

Fast and easy online submission: online submission at http://mc.manuscriptcentral.com/jcnur.

Early View: rapid online publication (with doi for referencing) for accepted articles in final form, and fully citable.

Positive publishing experience: rapid double-blind peer review with constructive feedback.

Online Open: the option to make your article freely and openly accessible to non-subscribers upon publication in Wiley Online Library, as well as the option to deposit the article in your preferred archive. 